\title{
Gambaran Siklus Menstruasi Dilihat Berdasarkan Tingkat Kecemasan Pada Siswi MAN 1 Kota Madiun
}

\author{
Cintika Yorinda Sebtalesy \\ Program Studi D-III Kebidanan, STIKES Bhakti Husada Mulia Madiun \\ Email : cintikayorindas@gmail
}

\begin{abstract}
ABSTRAK
Masa remaja adalah perpindahan dari masa pubertas menuju masa dewasa. Perubahan fisik, psikologi dan sosial banyak berubah selama masa ini. Di Indonesia prevalensi terkait gangguan kecemasan menurut hasil Riset Kesehatan Dasar (Riskesdas) pada tahun 2013 memperlihatkan bahwa sebesar enam persen untuk usia lima belas tahun ke atas atau sekitar empat belas juta penduduk di Indonesia terjadi banyak gangguan mental emosional dengan menunjukkan gejala-gejala kecemasan dan depresi. Berat badan, aktivitas fisik, stress dan kecemasan, diet, paparan lingkungan dan kondisi kerja berpengaruh terhadap siklus menstruasi.

Jenis penelitian ini adalah deskriptif kuantitatif yang dilakukan di MAN 1 Kota Madiun pada Januari-April 2017. Pengambilan sampel menggunakan purposive sampling sejumlah 95 responden sesuai dengan kriteria inklusi dan eksklusi. Teknik pengumpulan data menggunakan skala gutman dan kuesioner HARS.

Hasil penelitian menunjukkan tingkat kecemasan pada siswi MAN 1 Kota Madiun paling banyak mempunyai tingkat kecemasan ringan dengan jumlah 58 siswi $(61,1 \%)$, tingkat kecemasan sedang sejumlah 26 siswi $(27,4 \%)$, tidak ada kecemasan sejumlah 9 siswi $(9,5 \%)$ dan tingkat keceasan berat ada 2 siswi $(2,1 \%)$. Mayoritas memiliki siklus menstruasi teratur yaitu sejumlah 52 siswi $(54,7 \%)$ dan memiliki siklus tidak teratur dengan jumlah 43 siswi $(45,3 \%)$.

Siklus ketika menstruasi dilihat berdasarkan tingkat kecemasan pada siswi MAN 1 Kota Madiun mayoritas responden mengalami siklus teratur dengan tingkat kecemasan ringan yaitu 34 responden $(35,8 \%)$ pada saat menstruasi.
\end{abstract}

Kata Kunci : Siklus Menstruasi, Siswi, Tingkat Kecemasan

\section{ABSTRACT}

Adolescence is a transition from puberty to adulthood. During this period, many teenagers experience changes both physically, psychologically and socially. In Indonesia, the prevalence of anxiety disorders according to the results of Basic Health Research (RISKESDAS) in 2013 showed that 6\% for people aged 15 years and over or around 14 million people in Indonesia experience mental emotional disorders that are indicated by symptoms of anxiety and depression. Factors that affect the menstrual cycle include weight, physical activity, stress and anxiety, diet, exposure to the environment and working conditions.

This type of research is descriptive quantitative conducted at MAN 1 Kota Madiun City in January-April 2017. The sampling of research was using purposive sampling 
amounted to 95 respondents according to inclusion and exclusion criteria. The data collection technique uses the gutman scale and the HARS questionnaire.

The results showed that the level of anxiety in Madiun City MAN 1 students had the highest level of mild anxiety with a total of 58 female students (61.1\%), moderate anxiety levels of 26 female students (27.4\%), no anxiety for 9 students $(9,5 \%)$ and the level of severe abuse is 2 female students (2.1\%). The majority had regular menstrual cycles of 52 students (54.7\%) and had irregular cycles with 43 female students (45.3\%).

The cycle when menstruation is seen based on the level of anxiety on the students of MAN 1 Kota Madiun, the majority of respondents experienced regular cycles with mild anxiety levels of 34 respondents (35.8\%) during menstruation.

Keywords: Menstruation Cycle, Female Student, Level of anxiety

\section{PENDAHULUAN}

Masa remaja adalah perpindahan dari masa pubertas menuju masa dewasa. Perubahan fisik, psikologi dan social banyak berubah selama masa ini. Usia 16 atau 17 tahun termasuk usia yang dikatakan sudah memasuki masa remaja antara dan usia 21 merupakan masa akhirnya. Dari masalah-masalah psikologis yang dialami remaja, salah satu masalah psikologi yang terjadi pada remaja yaitu kecemasan. Dalam sebuah berita elektronik mengungkapkan remaja sebelumnya lebih tahan terhadap terpaan kecemasan daripada generasi remaja masa kini. bahwa remaja masa kini lebih mudah mengalami kecemasan dibanding remaja pada generasi sebelumnya dikarenakan tuntuttan akademik saat ini lebih dibanding jaman orangtuaanya dahulu (Herri, 2012).

Kelompok usia remaja di dunia sejumlah 1,2 milyar atau $18 \%$ dari jumlah penduduk dunia (WHO, 2014). Menurut profil kesehatan Indonesia tahun 2013 menunjukan bahwa jumlah penduduk perempuan Indonesia pada tahun 2013 yang berusia 15-19 tahun sebanyak 10.729.820 orang dan yang berusia $20-24$ tahun sebanyak 10.453.214 orang. Menurut Peraturan Menteri Kesehatan RI nomer 25 tahun 2014 remaja adalah penduduk dalam rentang usia sepuluh sampai empat belas tahun di Indonesia menurut sensus penduduk 2010 sejumlah
43,5 juta atau sekitar $18 \%$ dari total penduduk. (Kementerian Kesehatan RI, 2013).

Dilaporkan bahwa perkiraan gangguan kecemasan pada dewasa muda di Amerika adalah sekitar 42 juta atau sekitar 8,1 \% orang hidup dengan gangguan kecemasan, seperti gangguan kepanikan, gangguan obsesif-kompulsiif, gangguan stres setelah trauma, gangguan kecemasan umum dan phobia, sedangkan gangguan kecemasan terkait jenis kelamin dilaporkan bahwa prevalensi gangguan kecemasan seumur hidup pada perempuan sejumlah $60 \%$ lebih tinggi daripada pria (Akbar, 2015).

Di Indonesia prevalensi terkait gangguan kecemasan menurut hasil Riskesdas pada tahun 2013 memperlihatkan bahwa sejumlah $6 \%$ untuk usia 15 tahun ke atas atau sekitar 14 juta penduduk di Indonesia terjadi gangguan mental emosional yang diperlihatkan dengan gejala-gejala kecemasan dan depresi (Kementerian Kesehatan RI, 2014). Hasil studi pendahuluan (survey pendahuluan) yang dilakukan pada tanggal 18 Februari tahun 2017 di MAN 1 Madiun didapat jumlah siswi kelas X dan kelas XI sejumlah 124 siswi dari 15 siswi sebanyak 10 siswi $(66,7 \%)$ dengan kecemasan berat, 5 siswi $(33,3 \%)$ dengan kecemasan sedang dan tidak ditemukan kecemasan ringan, kecemasan yang dialami siswi tersebut 
karena hubungan interpersonal, lingkungan hidup, keuangan, perkembangan, keluarga Dan trauma. Selain data tentang tingkat kecemasan di dapatkan pula data siswi tentang siklus menstruasinya terdapat 11 siswi yang siklusnya teratur, 3 siswi yang siklusnya panjang serta 1 siswi yang siklusnya pendek.

Gejala kecemasan baik akut maupun kronik merupakan komponen utama bagi hampir semua gangguan psikiatrik. Kecemasan akan meningkatkan kemungkinan terjadinya depresi bahkan bunuh diri Kecemasan sebagai rangsangan melalui system saraf diteruskan ke susunan saraf pusat yaitu limbik system melalui tranmisi saraf, selanjutnya melalui saraf autonom (simpatis atau parasimpatis) akan dilanjutkan ke kelenjar hormonal (endokrin) hingga mengeluarkan sekret (cairan) neurohormonal menuju hiphofisis melalui system prontal guna mengeluarkan gonadotropin dalam bentuk FSH (Follikel Stimulazing Hormone) dan LH (Leutinizing Hormone). Produksi kedua hormon tersebut adalah dibawah pengaruh RH (Realezing Hormone) yang disalurkan dari hipotalamus ke hipofisis. Pengeluaran RH sangat dipengaruhi oleh mekanisme umpan balik estrogen terhadap hipotalamus hingga selanjutnya mempengaruhi terjadinya proses menstruasi atau haid (Prawirohardjo, 2009).

Menstruasi adalah perdarahan yang disebabkan oleh terkikisnya dinding bagian dalam rahim (endometrium) yang terkandung pembuluh darah. Bagian endometrium dipersiapkan untuk penempelan embrio. Jika tidak terjadi implantasi embrio bagian ini akan terkikis, darah keluar melalui jalan lahir. Perdarahan ini terjadi secara berkala, rentang waktu antara menstruasi awalan dengan menstruasi berikutnya dikenal dengan satu siklus menstruasi (Irianto, 2015).

Siklusmenstruasi merupakan waktu sejak hari pertama menstruasi sampai datangnya menstruasi periode berikutnya, sedangkan panjang siklus menstruasi adalah jarak antara tanggal mulainya menstruasi yang lalu dan mulainya menstruasi berikutnya. Siklus menstruasi pada wanita normalnya berkisar antara 21-32 hari dan hanya 10$15 \%$ yang memiliki siklus menstruasi 28 hari dengan lama menstruasi 3-5 hari, ada yang 7-8 har (Proverati, 2009). Menurut Kusmiran (2013), faktor yang mempengaruhi siklus menstruasi diantaranya $\mathrm{BB}$, aktivitas fisik, stress dan kecemasan, diet, terpapar lingkungan dan kondisi kerja. Dalam mencegah serta mengatasi kecemasan antara lain upaya meningkatkan kekebalan terhadap stress, terapi somatik, psikoterapi, serta terapi psikoreligius (Hawari 2008).

\section{METODE}

Metode yang dipergunakan dalam penelitian ini adalah deskriptif kuantitatif yaitu metodologi deskriptif kuantitatif, metode yang digunakan untuk memahami nilai variabel mandiri, baik satu variabel atau lebih (independen) tanpa menggunakan perbandingan atau dihubungkan dengan variabel yang lain (Sugiyono, 2015).

Subyek penelitian ini yaitu siswi MAN 1 Kota Madiun yang sudah mengalami menstruasi yang bersekolah di MAN 1 Kota Madiun dengan waktu penelitian Januari-April tahun 2017.

Instrumen penelitian yang digunakan auntuk siklus menstruasi yaitu skala guttman dan kuesioner HARS untuk mengukur tingkat kecemasan.

Pengambilan sampel menggunakan purposive sampling sejumlah 95 responden sama dengan parameter inklusi dan eksklusi. 
Proses mengumpulkan data pada penelitian ini mengambil data secara langsung ke siswi MAN 1 Kota Madiun dengan melakukan perkenalan diri terlebih dahulu serta menjelaskan cara pengisian mengenai kuesioner yang sudah diberikan kepada siswi MAN 1 Kota Madiun.

Langkah-langkah analisa data penelitian ini yaitu :

1. Pemeriksaan data

Data diperoleh dari hasil pengisian kuesioner kemudian kuesioner dikumpulkan kembali untuk dianalisis selanjutnya.

2. Tabulasi data

Data dikumpulkan kemudian dilakukan tabulasi yang berarti dimasukkan data ke dalam tabel.

3. Menghitung frekuensi data

Selanjutnya data ditabulasikan kemudian dihitung frekuensinya masingmasing, data yang sudah ditabulasikan.

4. Memvisualisasikan data

Setelah data dihitung frekuensinya kemudian divisualisasikan menggunakan tabel.

5. Menafsirkan data

Data yang telah divisualisasikan dalam bentuk tabel kemudian ditafsirkan dengan bentuk deskriptif atau teks yang bersifat naratif.

\section{HASIL DAN PEMBAHASAN Gambaran Umum Lokasi Penelitian}

MAN 1 Kota Madiun yakni salah satu SMA negeri yang berdiri di kota Madiun. Lokasinya ada di Jalan Soekarno Hatta 68 B Demangan Kota Madiun, Jawa Timur Indonesia. Sekolah ini adalah sekolah negeri yang berbasis Madrasah Aliyah yaitu sekolah dimana terdapat tambahan pelajaran tentang agama di dalamnya. Jumlah kelas yang dimiliki sekolah ini terdapat 2 kelas setiap jenjang tingkatan dan jurusan seperti untuk jurusan IPA terdapat IPA 1, IPA 2. Di sekolah ini terdapat kelas $\mathrm{X}$, XI dan XI yang rata - rata jumlah siswa putri lebih banyak dari pada siswa laki - laki.

Jurusan yang terdapat di sekolah ini ada 3 yaitu IPA, IPS serta Agama. Sekolah ini dilengkapi dengan kantin, lapangan, ruang guru, UKS, tempat ibadah, aula, serta beberapa ruang kelas yang mengitari lapangan yang berada ditengahnya serta tampak segar karena di setiap sudut terdapat tanaman hijau yang terjajar rapi.

Karakteristik Umur Responden

Tabel 1. Distribusi Frekuensi Responden Remaja Putri Berdasarkan Umur

\begin{tabular}{cccc}
\hline No & Umur & $\begin{array}{c}\text { Frekuensi ( } \\
\text { n ) }\end{array}$ & $\begin{array}{c}\text { Prosentasi ( } \\
\text { \% })\end{array}$ \\
\hline 1. & $\begin{array}{c}12-15 \\
\text { tahun }\end{array}$ & 6 & 6,3 \\
\hline 2. & $\begin{array}{c}16-19 \\
\text { tahun }\end{array}$ & 89 & 93,7 \\
\hline & Jumlah & 95 & 100
\end{tabular}

Sumber data : Data primer (2017)

Berdasarkan hasil tabulasi dan penghitungan frekuensi didapatkan hasil bahwa sebagian besar remaja putri kelas X dan XI di MAN 1 Kota Madiun merupakan remaja penuh berumur $16-19$ tahun sebanyak 89 siswi $(93,7 \%)$ dan sebagian kecil remaja putri kelas X dan XI di MAN 1 Kota Madiun merupakan remaja muda berumur 12 - 15 tahun sebanyak 6 siswi $(6,3 \%)$.

\section{Tingkat Kecemasan Responden}

Tabel 2. Distribusi Frekuensi Responden Berdasar Tingkat Kecemasan

\begin{tabular}{cccc}
\hline No & $\begin{array}{c}\text { Tingkat } \\
\text { Kecemasan }\end{array}$ & $\begin{array}{c}\text { Frekuensi } \\
(\mathbf{n})\end{array}$ & $\begin{array}{c}\text { Prosentasi } \\
(\boldsymbol{\%})\end{array}$ \\
\hline 1. & $\begin{array}{c}\text { Tidak ada } \\
\text { kecemasan }\end{array}$ & 9 & 9,5 \\
\hline 2. & $\begin{array}{c}\text { Kecemasan } \\
\text { ringan }\end{array}$ & 58 & 61,1 \\
\hline 3. & $\begin{array}{c}\text { Kecemasan } \\
\text { sedang }\end{array}$ & 26 & 27,4 \\
\hline 4. & $\begin{array}{c}\text { Kecemasan } \\
\text { berat }\end{array}$ & 2 & 100 \\
\hline & Jumlah & 95 & 2,1 \\
\hline
\end{tabular}

Sumber data : Data primer (2017) 
Berdasarkan tabulasi diatas dapat dijelaskan bahwa sebagian besar tingkat kecemasan remaja putri di MAN 1 Kota Madiun merupakan tingkat kecemasan ringan sebanyak 58 siswi ( $61,1 \%$ ) dan sebagian kecil merupakan tingkat kecemasan berat sebanyak 2 siswi $(2,1$ $\%)$.

Siklus Menstruasi Responden

Tabel 3. Distribusi Frekuensi Responden Berdasar

\begin{tabular}{cccc}
\multicolumn{4}{c}{ Siklus Menstruasi } \\
\hline No & $\begin{array}{c}\text { Siklus } \\
\text { Menstruasi }\end{array}$ & $\begin{array}{c}\text { Frekuen } \\
\text { si }(\mathbf{n})\end{array}$ & $\begin{array}{c}\text { Prosentasi } \\
(\mathbf{\%})\end{array}$ \\
\hline 1. & Teratur & 43 & 45,3 \\
\hline 2. & Tidak teratur & 52 & 54,7 \\
\hline & Jumlah & 95 & 100
\end{tabular}

Sumber data : Data primer (2017)

Berdasarkan tabulasi diatas dapat dijelaskan bahwa sebagian besar siklus menstruasi remaja putri di MAN 1 Kota Madiun merupakan siklus menstruasi tidak teratur sebanyak 52 siswi ( 54,7 \% ) dan sebagian kecil merupakan siklus menstruasi teratur sebanyak 43 siswa ( $45,3 \%)$.

\section{Frekuensi Tingkat Kecemasan Dengan Siklus Menstruasi Responden}

Tabel 4. Distribusi Frekuensi Silang Antara Tingkat Kecemasan dengan Siklus Menstruasi

\begin{tabular}{|c|c|c|c|c|c|c|}
\hline \multirow{3}{*}{$\begin{array}{c}\text { Tingkat } \\
\text { Kecemasan }\end{array}$} & \multicolumn{5}{|c|}{ Siklus menstruasi } & \multirow[t]{3}{*}{ Tota } \\
\hline & \multicolumn{2}{|c|}{ Teratur } & \multicolumn{3}{|c|}{ Tidak teratur } & \\
\hline & $\mathrm{F}$ & $\%$ & $\mathrm{~F}$ & $\%$ & F \% & \\
\hline $\begin{array}{l}\text { Tidak ada } \\
\text { kecemasan }\end{array}$ & 9 & 9,5 & 0 & 0 & 9 & 9,5 \\
\hline $\begin{array}{c}\text { Kecemasan } \\
\text { ringan }\end{array}$ & 34 & 35,8 & 24 & 25,3 & 58 & 61,1 \\
\hline $\begin{array}{c}\text { Kecemasan } \\
\text { sedang }\end{array}$ & 0 & 0 & 26 & 27,4 & 26 & 27,4 \\
\hline $\begin{array}{c}\text { Kecemasan } \\
\text { berat }\end{array}$ & 0 & 0 & 2 & 2,1 & 2 & 2,1 \\
\hline Total & 43 & 45,3 & 52 & 54,7 & 95 & 100 \\
\hline P Value & & & 0,00 & & & \\
\hline
\end{tabular}

Sumber data : Data primer (2017)

Berdasarkan tabulasi diatas dapat dijelaskan bahwa hasil analisis terbanyak antara tingkat kecemasan dengan siklus menstruasi teratur diperoleh tidak ada kecemasan terbanyak adalah siklus menstruasi teratur sebesar 9 siswi ( 9,5\% ), kecemasan ringan terbanyak adalah siklus menstruasi teratur sebesar 34 siswi ( $35,8 \%$ ), kecemasan sedang terbanyak adalah siklus menstruasi tidak teratur sebesar 26 siswi ( $27,4 \%)$, serta kecemasan berat terbanyak adalah siklus menstruasi tidak teratur sebesar 2 siswi $(2,1 \%)$.

\section{PEMBAHASAN}

Berdasarkan analisis data penelitian dapat diketahui bahwa dari 95 responden remaja putri di MAN 1 Kota Madiun di dapatkan data bahwa siklus menstruasi terbanyak adalah siklus menstruasi tidak teratur sejumlah 52 siwsi atau sebesar 54,7 \%. Sedangkan didapatkan hasil siklus menstruasi terendah pada remaja putri di MAN 1 kota madiun adalah siklus menstruasi teratur. Pada remaja putrid di MAN 1 Kota Madiun ditemukan sebanyak 43 siswi ( $45,3 \%$ ) yang mengalami siklus menstruasi yang tidak teratur.

Menstruasi ialah perdarahan yang terjadi akibat terkikisnya dinding sebelah dalam rahim (endometrium) yang banyak mengandung pembuluh darah. Lapisan endometrium dipersiapkan untuk implantasi embrio. Jika tidak terjadi implantasi embrio lapisan ini akan luruh, darah keluar melalui serviks dan vagina. Perdarahan ini terjadi secara berkala, rentang waktu antara menstruasi awal dengan menstruasi berikutnya dikenal dengan satu siklus menstruasi (Irianto, 2015).

Kecemasan akan meningkatkan kemungkinan terjadinya depresi bahkan bunuh diri Kecemasan sebagai rangsangan melalui sistem saraf diteruskan ke susunan saraf pusat yaitu limbik system melalui tranmisi saraf, selanjutnya melalui saraf autonom (simpatis atau parasimpatis) akan dilanjutkan ke kelenjar hormonal (endokrin) hingga mengeluarkan sekret (cairan) neurohormonal menuju hiphofisis 
melalui sistem prontal guna mengeluarkan gonadotropin dalam bentuk FSH (Follikel Stimulazing Hormone) dan LH (Leutinizing Hormone). Produksi kedua hormon tersebut adalah dibawah reaksi RH (Realezing Hormone) yang disampaikan dari hipotalamus ke hipofisis. Mekanisme feedback estrogen memperngaruhi pengeluaran $\mathrm{RH}$ terhadap hipotalamus hingga selanjutnya mempengaruhi terjadinya proses menstruasi atau haid (Prawirohardjo, 2009).

Siklus menstruasi merupakan waktu sejak hari pertama menstruasi sampai datangnya menstruasi periode berikutnya, sedangkan panjang siklus menstruasi adalah jarak antara tanggal mulainya menstruasi yang lalu dan mulainya menstruasi berikutnya. Siklus menstruasi pada wanita normalnya berkisar antara 21-32 hari dan hanya 10 $15 \%$ yang memiliki siklus menstruasi 28 hari dengan lama menstruasi 3-5 hari, ada yang 7-8 har (Proverati, 2009). Siklus menstruasi tidak teratur yaitu jika siklus menstruasi yang terjadi abnormal atau dengan kata lain tidak berada pada jarak pola menstruasi dengan rentang kurang dari 21 hari (polimenorea), lebih dari 35 hari (oligomenorea) serta rentang selama 90 hari atau lebih tidak menstruasi (amenorea) (Wahyuningrum, 2016). Menurut Wahyuningrum 2016 pada wanita siklus menstruasi seringkali terjadi perubahan serta yang dimaksud siklus menstruasi teratur adalah siklus menstruasi dengan rentang waktu $21-35$ hari. Berlangsung dengan siklus sama selama 3 bulan. Menurut Kusmiran (2013), komponen yang mempengaruhi perputaran mekanisme menstruasi yaitu $\mathrm{BB}$, aktivitas fisik, stress dan kecemasan, diet, terpapar lingkungan dan kondisi kerja.

Siklus menstruasi merupakan waktu sejak hari pertama menstruasi sampai datangnya menstruasi periode berikutnya, sedangkan panjang siklus menstruasi adalah jarak antara tanggal mulainya menstruasi yang lalu dan mulainya menstruasi berikutnya. Siklus menstruasi pada wanita normalnya berkisar antara 21-32 hari dan hanya 10 $15 \%$ yang memiliki siklus menstruasi 28 hari dengan lama menstruasi 3-5 hari, ada yang 7-8 hari (Proverati, 2009). Menurut Kusmiran, 2011 siklus menstruasi dipengaruhi oleh BB, aktivitas fisik, stress dan kecemasan, diet, terpapar lingkungan dan kondisi kerja. Kecemasan akan meningkatkan kemungkinan terjadinya depresi bahkan bunuh diri Kecemasan sebagai rangsangan melalui system saraf diteruskan ke susunan saraf pusat yaitu limbik system melalui tranmisi saraf, selanjutnya melalui saraf autonom (simpatis atau parasimpatis) akan meneruskan ke kelenjar-kelenjar hormonal (endokrin) hingga mengeluarkan sekret (cairan) neurohormonal menuju hiphofisis melalui system prontal guna mengeluarkan gonadotropin dalam bentuk FSH (Follikel Stimulazing Hormone) dan LH (Leutinizing Hormone). Produksi kedua hormon tersebut adalah dibawah perintah RH (Realezing Hormone) yang disampaikan dari hipotalamus ke hipofisis. Pengeluaran RH sangat dipengaruhi oleh cara kerja umpan balik estrogen terhadap hipotalamus hingga selanjutnya mempengaruhi terjadinya proses menstruasi atau haid (Prawirohardjo, 2007).

Sesuai dari hasil penelitian ini masyarakat dapat memahami bahwa menstruasi yang tidak teratur dapat disebabkan oleh kecemasan untuk itu untuk petugas kesehatan diharapkan dapat memberika penyuluhan dan pendidikan ke masyarakat terkait kecemasan sehingga terjadinya siklus menstruasi yang tidak teratur dapat dihindari serta remaja putri dapat mengenali gejala - gejala 
kecemasan sehingga siklus menstruasi tidak teratur dapat dihindari.

\section{SIMPULAN}

Tingkat kecemasan remaja putri di MAN 1 Kota Madiun sebagian besar merupakan kecemasan ringan.

Siklus menstruasi remaja putri di MAN 1 Kota Madiun sebagian besar merupakan siklus menstruasi tidak teratur.

Siklus ketika menstruasi dilihat berdasarkan tingkat kecemasan pada siswi MAN 1 Kota Madiun mayoritas responden mengalami siklus teratur dengan tingkat kecemasan ringan yaitu 34 responden $(35,8 \%)$ pada saat menstruasi.

\section{SARAN}

\section{Bagi Siswi MAN 1 Kota Madiun}

Siswi MAN 1 Kota Madiun agar senantiasa meningkatkan pengetahuannya mengenai menstruasi untuk mengurangi tingkat kecemasan saat menstruasi.

\section{Bagi MAN 1 Kota Madiun}

Untuk MAN 1 Kota Madiun agar memasukkan materi mengenai menstruasi dan kesehatan reproduksi ke dalam kegiatan akademik untuk meningkat pengetahuan siswa mengenai kesehatan reproduksi khususnya menstruasi.

\section{Bagi Peneliti Selanjutnya}

Peneliti selanjutnya agar dapat menggunakan hasil penelitian ini sebagai acuan untuk melakukan penelitian selanjutnya mengenai faktor lain yang mempengaruhi siklus menstruasi.

\section{DAFTAR PUSTAKA}

Akbar. (2015) Hubungan Kecemasan Dengan Prestasi Akademik Mahasiswa di Fakultas Psikologi Universitas Muhhamadiyah Surakarta.

Hawari, D. (2008). Manajemen Stres Cemas dan Depresi. Jakarta : Balai Penerbit FKUI

Herri. (2012). Pengantar Psikologi Dalam Keperawatan. Jakarta : Kencana Pranada Media Group

Irianto. (2015). Kesehatan Reproduksi. Bandung : Alfabet

Kementerian Kesehatan RI. (2013). Profil Kesehatan Indonesia. Jakarta : Kementerian Kesehatan RI

Kusmiran, E. (2013). Kesehatan Reproduksi Remaja dan Wanita. Jakarta : Salemba Medika

Prawirohardjo, S. (2009). Ilmu Kandungan. Jakarta : Yayasan Bina Pustaka.

Proverawati. (2009). Menarche Menstruasi Pertama Penuh Makna. Yoyakarta : Nuha Medika.

Sugiyono. (2015). Metode Penelitian Kuantitatif, Kualitatif R \& D. Bandung : Alfabeta.

Wahyuningrum. (2016). Hubungan Tingkat Stres Dengan Siklus Menstruasi Pada Mahasiswa Kebidanan Tingkat I dan II Poltekes Bhakti Mulia Sukoharjo. 